\title{
Long Noncoding RNA ST7-ASI Upregulates TRPM7 Expression by Sponging microRNA-543 to Promote Cervical Cancer Progression
}

This article was published in the following Dove Press journal: OncoTargets and Therapy

\section{Hongguo Qi \\ Lianwei $\mathrm{Lu}^{2}$ \\ Lili Wang ${ }^{3}$}

'Department of Gynaecology and Obstetrics, The Second Children \& Women's Healthcare of Jinan City, Jinan, Shandong 250022, People's Republic of China; ${ }^{2}$ Department of Radiology, Weifang Binhai Economic and Technological Development Zone People's Hospital, Weifang, Shandong 26I108, People's Republic of China; ${ }^{3}$ Department of Gynaecology and Obstetrics, The 5th People's Hospital of Jinan, Jinan, Shandong 250022, People's Republic of China
Correspondence: Lili Wang Department of Gynaecology and Obstetrics, The 5th People's Hospital of Jinan, 24297 Jingshi Road, Jinan, Shandong 250022, People's Republic of China Email wanglili_5th@yeah.net
Purpose: ST7 antisense RNA 1 (ST7-AS1) is a long noncoding RNA that affects the progression of gastric cancer and laryngeal squamous cell carcinoma. Herein, ST7-AS1 expression was detected in cervical cancer tissues and cell lines. In addition, its biological roles in inducing the aggressive phenotype of cervical cancer and its associated mechanisms of action were illustrated.

Patients and Methods: ST7-AS1 expression in cervical cancer tissues and cell lines was detected using quantitative real-time polymerase chain reaction (qRT-PCR). Malignancy was determined using Cell Counting Kit-8 assay, flow cytometry, transwell migration and invasion assays, and xenograft experiments. Bioinformatics analysis was performed to predict the interaction between ST7-AS1 and microRNA-543 (miR-543). Luciferase reporter assay, RNA immunoprecipitation assay, Western blotting, qRT-PCR, and rescue experiments were performed to further identify the interactions among ST7-AS1, miR-543, and transient receptor potential melastatin 7 (TRPM7).

Results: ST7-AS1 was upregulated in cervical cancer tissues and cell lines. ST7-AS1 overexpression was correlated with a high International Federation of Gynecology and Obstetrics stage, frequent lymph node metastasis, deep cervical invasion, and short overall survival in patients with cervical cancer. ST7-AS1 inhibition hindered cervical cancer cell proliferation, migration, and invasion; ST7-AS1 downregulation resulted in marked cell apoptosis. Additionally, ST7-AS1 deficiency restricted cervical tumor growth in vivo. Mechanistically, ST7-AS1 functioned as competing endogenous RNA to increase TRPM7 expression by sponging miR-543. Intriguingly, rescue experiments revealed that miR-543 downregulation or TRPM7 overexpression abrogated the inhibitory actions of ST7-AS1 knockdown in the aggressive phenotype of cervical cancer cells.

Conclusion: The newly identified ST7-AS1/miR-543/TRPM7 axis promoted the oncogenicity of cervical cancer cells both in vitro and in vivo. Our study highlighted the importance of this novel axis in cervical cancer progression, suggesting that this pathway can serve as a promising therapeutic target for cervical cancer.

Keywords: ST7 antisense RNA 1, cervical cancer, transient receptor potential melastatin 7, microRNA-543

\section{Introduction}

Cervical cancer ranks second among the most common human cancers and is the fourth leading cause of cancer-related deaths among women globally. ${ }^{1}$ Approximately half a million new cervical cancer cases are reported worldwide annually, accounting for $5 \%$ of all new cancer cases. Its incidence is high in 
developing and underdeveloped countries. ${ }^{2}$ Moreover, approximately 275,000 deaths from cervical cancer occur worldwide annually. ${ }^{3}$ A great deal of effort is expended to advance therapeutic methods including surgical excision, radiation therapy, and chemotherapy; however, the clinical response of patients with cervical cancer remains unsatisfactory, perhaps because of frequent postoperative recurrence, chemoresistance, and/or radioresistance. ${ }^{4}$ Human papillomavirus infection is a major pathogenic factor for cervical cancer. ${ }^{5}$ However, this infection alone is not sufficient for the initiation and progression of the malignancy. Hence, exploring biological mechanisms underlying the pathophysiology of cervical cancer is crucial to identify promising therapeutic interventions.

Long noncoding RNAs (lncRNAs) are a subgroup of endogenous RNAs, which comprise approximately 22 nucleotides. ${ }^{6}$ IncRNAs have no or weak protein-coding ability, but these have recently emerged as crucial molecules implicated in gene regulation at the transcriptional, post-transcriptional, and post-translational levels. ${ }^{7}$ In the past decades, studies have revealed important actions of IncRNAs during normal development, carcinogenesis, and cancer progression. ${ }^{8-10}$ Many lncRNAs are aberrantly expressed in cervical cancer and exhibit both cancerinhibiting or cancer-promoting functions. ${ }^{11}$ Involvement of dysregulated IncRNAs in the development of early biological characteristics of cervical cancer, including cell proliferation, apoptosis, and invasion; metastasis; radiosensitivity; angiogenesis; and epithelial-mesenchymal transition, has largely been identified. ${ }^{12-14}$

MicroRNAs (miRNAs) are a group of short, noncoding RNA transcripts that comprise 17-24 nucleotides. ${ }^{15}$ They function as post-transcriptional regulators of target mRNAs through direct binding to their 3 '-untranslated regions (UTRs), thereby resulting in translational repression and mRNA degradation. ${ }^{16,17}$ Previous studies have reported on the dysregulation of numerous miRNAs in cervical cancer, and this dysregulation may contribute to oncogenesis by modulating multiple malignant properties. ${ }^{18-20}$ A large body of evidence indicates that lncRNAs sequester miRNAs by acting as molecular sponges. This action produces inhibitory effects on the downstream target mRNAs of lncRNAs, thus facilitating their translation. Accordingly, therapies targeting lncRNA/ miRNA axes may be a novel approach to manage cervical cancer.

ST7 antisense RNA 1 (ST7-AS1) is an lncRNA that regulates the progression of gastric cancer ${ }^{21}$ and laryngeal squamous cell carcinoma. ${ }^{22}$ Nevertheless, the expression and function of ST7-AS1 in cervical cancer have not been elaborated. In this context, the present study aimed to explore the expression status and clinical significance of ST7-AS1 in cervical cancer. The biological roles of ST7AS1 in malignant phenotypes of cervical cancer cells both in vitro and in vivo were determined. Moreover, the mechanisms underlying the effects of ST7-AS1 on cervical cancer progression were elucidated.

\section{Patients and Methods}

\section{Patients and Clinical Tissues}

The Human Ethics Committee of the $5^{\text {th }}$ People's Hospital of Jinan approved the implemented protocols. The present study was conducted in accordance with the Declaration of Helsinki. In addition, written informed consent was obtained from all participants. Human cervical cancer tissues and their paired noncancerous tissues were collected from 65 patients recruited from the 5th People's Hospital of Jinan. Multiple literatures used the age of 55 years as the basis in cervical cancer patients. ${ }^{13,23,24}$ According, 55 years old is used as the basis, and all patients with cervical cancer were divided as groups: < 55 years and $\geq 55$ years. No systemic or local anticancer treatments were administered to these participants prior to surgical resection. The dissected clinical specimens were immediately frozen and preserved in liquid nitrogen.

Multiple studies have reported that cytoreductive surgery followed by intraperitoneal and intravenous chemotherapy can improve the clinical outcomes and quality of life of patients with advanced or distant metastasis of cervical cancer, ${ }^{25-28}$ hence, the 37 patients with cervical cancer diagnosed with stage III-IV admitted in the current study received cytoreductive surgery alongside intraperitoneal and intravenous chemotherapy.

The depth of cervical cancer infiltration is mainly judged by pathological diagnosis. The cervical/uterine wall, starting from the basal layer of the covering epithelium to the outermost layer of the cervical canal or uterine wall (serous membrane), is roughly divided into three segments. If the infiltration depth exceeds $2 / 3$ of the wall, it is considered as $\geq 2 / 3$; conversely, if the infiltration depth does not exceed $2 / 3$ of the wall, it is considered $<2 / 3$.

\section{Cell Lines}

The normal human cervical epithelial cell line Ect1/E6E7 was purchased from American Type Culture Collection 
(Manassas, VA, USA) and cultured in keratinocyte serumfree medium (Gibco; Thermo Fisher Scientific, Inc., Waltham, MA, USA) containing $0.1 \mathrm{ng} / \mathrm{mL}$ human recombinant epidermal growth factor, $0.05 \mathrm{mg} / \mathrm{mL}$ bovine pituitary extract, and $0.4 \mathrm{mM}$ calcium chloride. Cervical cancer cell lines, including C-33A, SiHa, CaSki, and HeLa, were obtained from the Shanghai Chinese Academy of Science (Shanghai, China). C-33A, SiHa, and HeLa cells were maintained on RPMI 1640 (Gibco; Thermo Fisher Scientific, Inc.), and CaSki cells were maintained on minimum essential media (Gibco; Thermo Fisher Scientific, Inc.). All media were supplemented with $10 \%$ fetal bovine serum (FBS; Gibco; Thermo Fisher Scientific, Inc.) and $1 \%$ penicillin/streptomycin. All cells were cultured in a humidified incubator with $5 \% \mathrm{CO}_{2}$ at $37^{\circ} \mathrm{C}$.

\section{Transfection}

Small interfering RNA (siRNA) specifically targeting ST7-AS1 (si-ST7-AS1\#1, si-ST7-AS2, and si-ST7AS1\#3), transient receptor potential melastatin 7 (TRPM7) siRNA (si-TRPM7), and negative control siRNA (si-NC) were produced by Generay Biotech (Shanghai, China). miR-543 mimic, miRNA NC mimic (miR-NC), miR-543 inhibitor, and NC inhibitor were obtained from RiboBio Technology (Guangzhou, China). Full-length TRPM7 amplified by GenePharma Technology (Shanghai, China) was subcloned into pcDNA3.1 sites to generate the pcDNA3.1/TRPM7 plasmid. The abovementioned oligonucleotides and plasmids were individually transfected or cotransfected into cells using Lipofectamine $^{\circledR} \quad 2000 \quad$ (Invitrogen; Thermo Fisher Scientific, Inc.).

\section{Quantitative Real-Time Polymerase Chain Reaction (qRT-PCR)}

Total RNA was extracted from tissues or cell lines using the TRIzol ${ }^{\circledR}$ reagent (Invitrogen; Thermo Fisher Scientific, Inc.). After quantification using the NanoDrop 2000 spectrophotometer (Thermo Fisher Scientific, Inc.), reverse transcription was performed using the miRcute miRNA cDNA First-Strand cDNA Synthesis Kit (TIANGEN BIOTECH; Beijing, China). miR-543 expression was determined via quantitative PCR using the miRcute enhanced miRNA qPCR Detection Kit (TIANGEN). U6 small nuclear RNA served as the internal reference gene for miR-543.
To quantify ST7-AS1 and TRPM7 expressions, total RNA was reverse-transcribed into cDNA using the PrimeScript RT Reagent Kit (Takara Biotechnology Ltd., Tokyo, Japan), followed by quantitative PCR using the SYBR Premix EX Taq Kit (Takara Biotechnology Ltd.). Glyceraldehyde-3-phosphate dehydrogenase (GAPDH) was used for the normalization of ST7-AS1 and TRPM7 expressions. Relative gene expression was calculated using the $2^{-\Delta \Delta \mathrm{Ct}}$ method.

\section{Subcellular Fractionation}

Nuclear and cytoplasmic fractions of cervical cancer cells were separated using the Cytoplasmic and Nuclear RNA Purification Kit (Norgen Biotek, Thorold, Canada). GAPDH and U6 were used as standards for subcellular fractionation.

\section{Cell Counting Kit-8 (CCK-8) Assay}

Cells transfected with oligonucleotides or plasmids were collected after 24 -h culture and seeded into 96 -well plates at a density of $2 \times 10^{3}$ cells/well. Cell proliferation was detected by incubating cells with $10 \mu \mathrm{L}$ CCK-8 cell solution (Dojindo Laboratories, Kumamoto, Japan) at $37^{\circ} \mathrm{C}$ and $5 \% \mathrm{CO}_{2}$ for $2 \mathrm{~h}$. Absorbance was measured at 450 $\mathrm{nm}$ using the Multiskan MK3 reader (Thermo Fisher Scientific, Inc.). Four time points $(0,24,48$, and 72 $\mathrm{h}$ after cell injection) were selected, and growth curves of absorbance ( $\mathrm{Y}$ axis) at each time point ( $\mathrm{X}$ axis) were plotted.

\section{Flow Cytometry}

The Annexin V-Fluorescein Isothiocyanate (FITC) Apoptosis Detection Kit (BioLegend, San Diego, CA, USA) was used to determine cell apoptosis. After digestion, transfected cells were washed with precooled phosphate-buffered saline (Gibco; Thermo Fisher Scientific, Inc.) and centrifuged, following which the supernatant was discarded. Subsequently, cells were double stained with $5 \mu \mathrm{L}$ FITC-annexin $\mathrm{V}$ and $5 \mu \mathrm{L}$ propidium iodide at room temperature for $15 \mathrm{~min}$ in the dark. Apoptosis rate was analyzed using a BD FACSCalibur flow cytometer (BD Biosciences, Franklin Lakes, NJ, USA).

\section{Transwell Migration and Invasion Assays}

Twenty-four-well transwell chambers with polycarbonate filters (pore size $=8 \mu \mathrm{m}$; BD Biosciences, San Jose, CA, USA) were used for transwell migration assay. After 48 $\mathrm{h}$ of cultivation, transfected cells were collected and 
resuspended in an FBS-free medium at a density of $5 \times$ $10^{5}$ cells $/ \mathrm{mL}$. The upper compartment of the transwell chambers was filled with $100 \mu \mathrm{L}$ cell suspension and the bottom compartment was filled with culture medium containing $20 \%$ FBS as a chemoattractant. After incubating for $24 \mathrm{~h}$, non-invading cells were scraped and washed off with a cotton bud. Thereafter, the invading cells were fixed in $4 \%$ paraformaldehyde and stained with $0.1 \%$ crystal violet. After obtaining images, five microscopic fields were randomly selected in each chamber and the invading cells were counted under an inverted microscope (Olympus Corporation, Tokyo, Japan). Matrigel-coated transwell chambers were used in transwell invasion assay, and the subsequent experimental steps were the same as those used in transwell migration assay.

\section{Xenograft Experiments}

Lentiviral vectors expressing short-hairpin RNA (shRNA) directed at silencing ST7-AS1 (sh-ST7-AS1) or negative control shRNA (sh-NC) were designed and produced by GenePharma Technology. Lentiviral vectors along with the packaging plasmids were cotransfected into $293 \mathrm{~T}$ cells, and the purified supernatant was transfected into $\mathrm{HeLa}$ cells. After transfection, HeLa cells were treated with $2 \mu \mathrm{g} / \mathrm{mL}$ puromycin for 2 weeks, generating cell lines stably expressing sh-ST7-AS1 or sh-NC.

All experimental procedures involving animals strictly complied with policies of the Animal Ethics Committee of the 5th People's Hospital of Jinan, and were conducted following the Animal Protection Law of the People's Republic of China-2009. Four- to six-week-old female BALB/c nude mice (Shanghai Experimental Animal Centre, Shanghai, China) were housed under specific pathogen-free conditions. The suspension $(200 \mu \mathrm{L})$ of HeLa cells stably expressing sh-ST7-AS1 or sh-NC $\left(1 \times 10^{7}\right.$ cells $)$ was subcutaneously injected into mice. Following injection, the volume of subcutaneous xenografts was monitored every week using the following equation: volume $=1 / 2 \times$ length $\times$ width $^{2}$. In the 5 th week, all mice were euthanatized and subcutaneous xenografts were excised, photographed, and weighed. Tumor xenografts were preserved in liquid nitrogen for RNA and protein isolation.

\section{Bioinformatics Analysis}

lncLocator (http://www.csbio.sjtu.edu.cn/bioinf/ IncLocator/), an lncRNA subcellular localization predictor, was used to predict cellular localization of ST7-AS1. The interaction between ST7-AS1 and miRNA(s) was analyzed using starBase 3.0 (http://starbase.sysu.edu.cn/).

\section{RNA Immunoprecipitation (RIP) Assay}

The EZ-Magna RIPTM RNA-Binding Protein Immunoprecipitation Kit (Millipore, Billerica, MA, USA) was used for RIP assay. Cells were lysed in complete RIP buffer with an RNase inhibitor and a protease inhibitor cocktail. The cell lysate $(100 \mu \mathrm{L})$ was incubated with magnetic beads conjugated with human anti-Ago2 antibody or anti-IgG antibody (Millipore). IgG was used as a negative control. Following treatment with proteinase $\mathrm{K}$ buffer, the immunoprecipitated RNA was used for qRTPCR to analyze ST7-AS1 and miR-543 enrichment.

\section{Luciferase Reporter Assay}

Fragments of TRPM7 carrying wild-type (wt) miR-543 binding sites or mutant (mut) TRPM7 fragments were amplified by GenePharma Technology and inserted into the pmirGLO luciferase reporter plasmid (Promega Corporation, Madison, WI, USA). This procedure yielded TRPM7-wt and TRPM7-mut recombinant luciferase reporter plasmids. ST7-AS1-wt and ST7-AS1-mut recombinant luciferase reporter plasmids were generated using similar experimental steps.

Regarding luciferase reporter assay, either wt or mut luciferase reporter plasmid, in combination with miR-543 mimic or miR-NC, was cotransfected into cervical cancer cells using Lipofectamine ${ }^{\circledR} 2000$. After 48 -h culture at $37^{\circ}$ $\mathrm{C}$ under $5 \% \mathrm{CO}_{2}$, a dual-luciferase reporter assay system (Promega Corporation) was used to quantify luciferase activity. Activity was normalized to that of Renilla luciferase.

\section{Western Blotting}

The cultured cells were collected and lysed in RIPA lysate buffer (Solarbio Life Science, Beijing, China) to obtain total proteins. After protein quantification, equal amounts of protein were subjected to $10 \%$ sodium dodecyl sulfatepolyacrylamide gel electrophoresis. Separated proteins were then transferred onto polyvinylidene fluoride membranes and blocked with 5\% non-fat milk at room temperature for $2 \mathrm{~h}$, followed by labeling at $4{ }^{\circ} \mathrm{C}$ overnight with primary antibodies against TRPM7 (ab135817; Abcam, Cambridge, MA, USA) or GAPDH (ab181602; Abcam). Thereafter, membranes were incubated with horseradish peroxidase-conjugated goat anti-rabbit IgG secondary antibody (ab205718; Abcam) at room 
temperature for $2 \mathrm{~h}$. Membranes were visualized with the ECL Prime Western Blotting Detection Reagent (GE Healthcare, Chicago, IL, USA).

\section{Statistical Analysis}

Data obtained in each experiment were collected and mean values were calculated. Chi-square test was performed to assess correlations among clinicopathological characteristics and ST7-AS1 expression in patients with cervical cancer. Student's $t$-test was performed to compare two groups. Differences among multiple groups were determined using one-way analysis of variance followed by Tukey's test. Survival curves were plotted using KaplanMeier analysis and analyzed using Log rank test. Correlation between ST7-AS1 and miR-543 expression was evaluated using Pearson's correlation coefficient. A P-value of $<0.05$ was considered statistically significant.

\section{Results}

\section{ST7-ASI Silencing Inhibits the Malignant Phenotype of Cervical Cancer Cells}

ST7-AS1 expression was detected in the 65 pairs of cervical cancer and noncancerous tissues using qRT-PCR. ST7-AS1 expression significantly increased in the cervical cancer tissues compared with that in the paired noncancerous tissues (Figure 1A). In addition, ST7-AS1 expression in four cervical cancer cell lines (C-33A, SiHa, CaSki, and HeLa) was higher than that in the normal epithelial cell line Ect1/E6E7 (Figure 1B).

The 65 patients with cervical cancer were classified into low and high ST7-AS1 expression groups according to median ST7-AS1 expression level in cervical cancer tissues. As shown in Table 1, elevated ST7-AS1 expression level was correlated with the International Federation of Gynecology and Obstetrics (FIGO) stage ( $\mathrm{P}=0.046)$, lymph node metastasis ( $\mathrm{P}=0.014)$, and depth of cervical invasion $(\mathrm{P}=0.023)$. Additionally, the high ST7-AS1 expression group showed significantly shorter overall survival than the low ST7-AS1 expression group (Figure 1C; $\mathrm{P}=0.027)$.

To reveal the detailed functions of ST7-AS1 in cervical cancer progression, ST7-AS1 was knocked down in $\mathrm{C}-33 \mathrm{~A}$ and $\mathrm{SiHa}$ cell lines, which originally presented the highest ST7-AS1 expression among the four cervical cancer cell lines. Transfection efficiency was assessed using qRT-PCR. si-ST7-AS1\#3 transfection resulted in the maximum inhibition of ST7-AS1 expression
(Figure 1D). Hence, si-ST7-AS1\#3 was renamed si-ST7AS1 and used in functional experiments. ST7-AS1 downregulation restricted the proliferation of $\mathrm{C}-33 \mathrm{~A}$ and $\mathrm{SiHa}$ cells (Figure 1E), whereas ST7-AS1 silencing evidently increased the proportions of apoptotic C-33A and $\mathrm{SiHa}$ cells (Figure 1F). Moreover, the effects of ST7-AS1 knockdown on the metastatic capacity of C-33A and SiHa cells were examined. ST7-AS1 knockdown hindered the migratory (Figure $1 \mathrm{G}$ ) and invasive (Figure $1 \mathrm{H}$ ) abilities of C-33A and SiHa cells. Taken together, these results indicate the cancer-promoting actions of ST7-AS1 in cervical cancer cells.

\section{ST7-ASI Functions as a Molecular Sponge of miR-543 in Cervical Cancer Cells}

The mechanism underlying the effects of ST7-AS1 was assessed initially by determining the cellular localization of ST7-AS1. IncLocator analysis indicated that ST7-AS1 was localized in the cytoplasm (Figure 2A). Subcellular fractionation followed by qRT-PCR showed that ST7-AS1 was primarily localized in the cytoplasm of C-33A and SiHa cells (Figure 2B). Thus, ST7-AS1 is a cytoplasmic lncRNA that may modulate gene expression at the posttranscriptional level.

Based on starBase 3.0 analysis, ST7-AS1 harbored a site complementary to the seed sequence of miR-543 (Figure 2C). To conduct follow-up assays, the transfection efficiency of miR-543 mimic in C-33A and SiHa cells was evaluated by qRT-PCR analysis and the results confirmed that miR-543 mimic effectively increased miR-543 expression in both C-33A and SiHa cells (Figure 2D). To verify this prediction, luciferase reporter assay was employed to test the binding association between ST7-AS1 and miR543. The luciferase activity of $\mathrm{C}-33 \mathrm{~A}$ and $\mathrm{SiHa}$ cells transfected with ST7-AS1-wt was substantially downregulated by miR-543 overexpression; however, the luciferase activity of ST7-AS1-mut was unaffected in response to miR-543 mimic cotransfection (Figure 2E). In addition, RIP assay showed that both ST7-AS1 and miR-543 conjugated with Ago2-rich magnetic beads (Figure 2F). Furthermore, qRT-PCR analysis showed that miR-543 expression was clearly elevated by ST7-AS1 depletion in C-33A and SiHa cells (Figure 2G). Furthermore, miR-543 expression was lower in the cervical cancer tissues than in the paired noncancerous tissues (Figure 2H). In the 65 cervical cancer tissues, miR-543 expression was inversely correlated with ST7-AS1 expression (Figure 2I; $\mathrm{r}=$ 
A

E

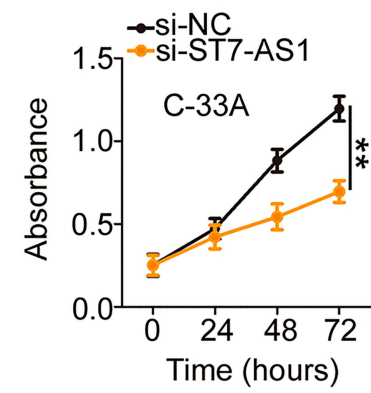

G
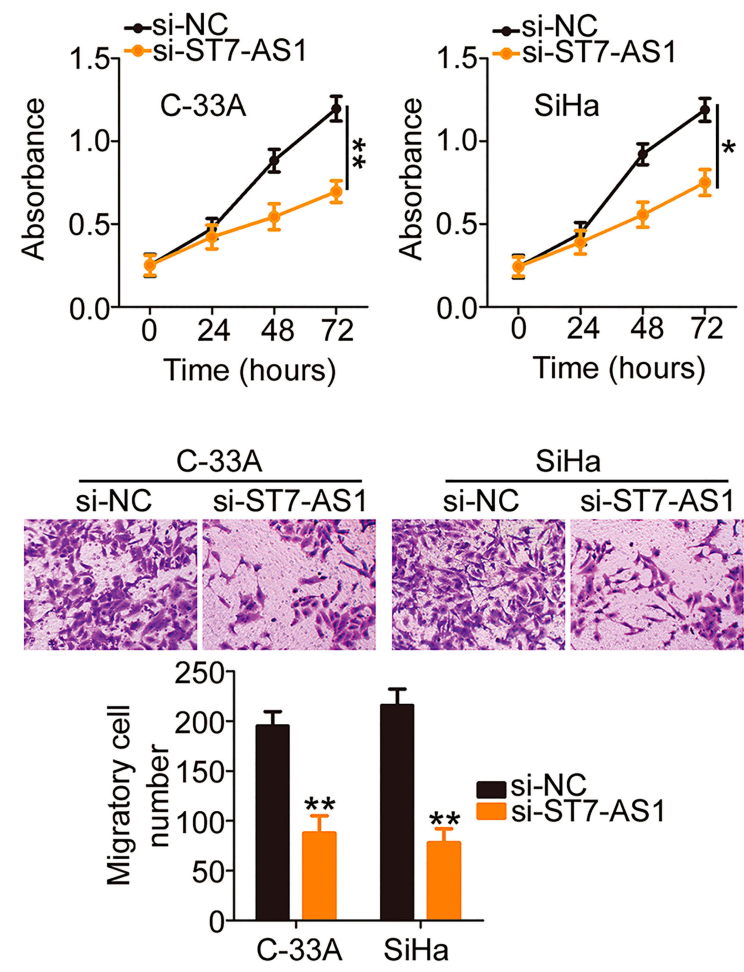

B

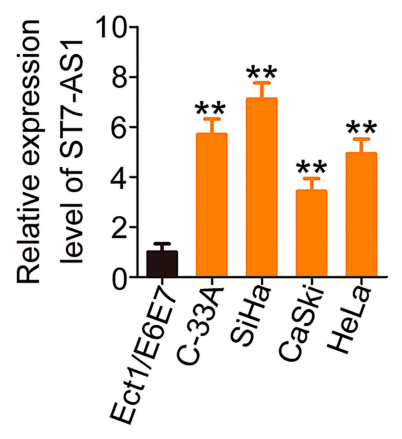

C

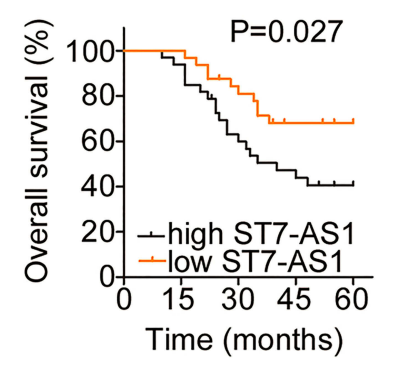

D

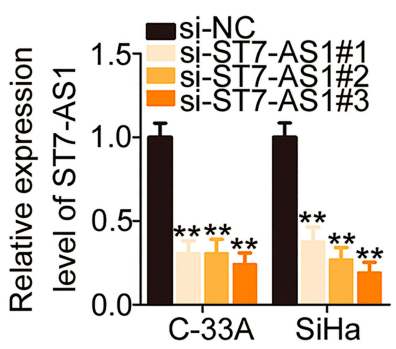

F
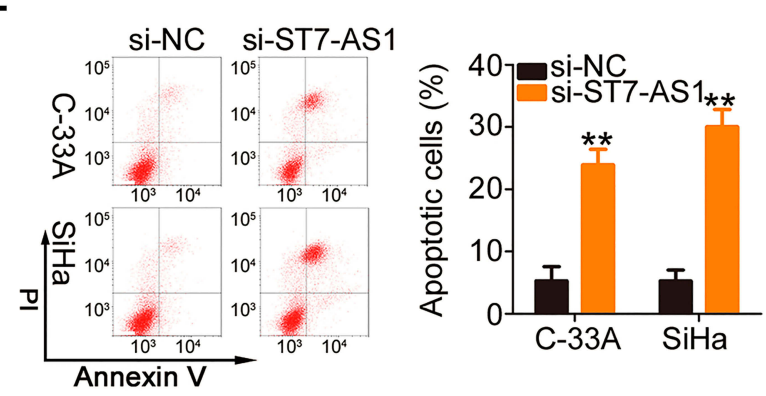

H
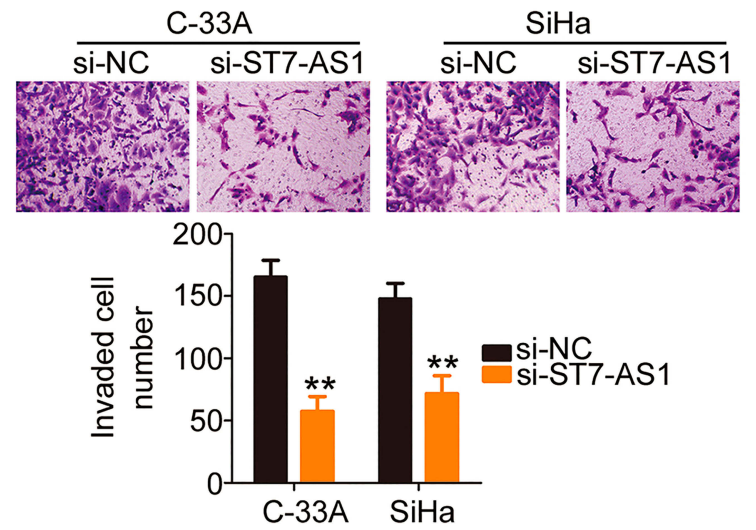

Figure I ST7-ASI silencing inhibits the malignant phenotype of C-33A and SiHa cells in vitro. (A) qRT-PCR was performed to detect ST7-ASI expression in 65 pairs of cervical cancer and noncancerous tissues. (B) ST7-ASI expression in four cervical cancer cell lines (C-33A, SiHa, CaSki, and HeLa) and the normal human cervical epithelial cell line Ectl/E6E7 was determined by qRT-PCR. (C) Data of patients with cervical cancer presenting with high or low ST7-ASI expression were subjected to Kaplan-Meier analysis $(P=0.027)$. (D) ST7-ASI expression in C-33A and SiHa cells following si-ST7-ASI or si-NC transfection was quantified using qRT-PCR. (E) CCK-8 assay was performed to detect the proliferation of si-ST7-ASI-transfected or si-NC-transfected C-33A and SiHa cells. (F) Apoptosis of C-33A and SiHa cells after ST7-ASI knockdown was examined using flow cytometry. $(\mathbf{G}$ and $\mathbf{H})$ Transwell migration and invasion assays were conducted to evaluate the migratory and invasive abilities of $C-33 \mathrm{~A}$ and $\mathrm{SiHa}$ cells following ST7-ASI silencing. $* \mathrm{P}<0.05$ and $* * \mathrm{P}<0.01$.

$-0.6236, \mathrm{P}<0.0001)$. Collectively, these outcomes suggest that ST7-AS1 acts as a molecular sponge of miR-543 in cervical cancer cells.

\section{ST7-ASI Regulates TRPM7, a Direct} Target of miR-543, Through miR-543 Sponging in Cervical Cancer Cells

TRPM7 was previously reported as a direct target of miR543 in cervical cancer cells. ${ }^{29}$ The putative binding sequences of miR-543 in the 3'-UTR of TRPM7 are shown in Figure 3A. qRT-PCR and Western blotting detected TRPM7 mRNA and protein expression levels in C-33A and SiHa cells overexpressing miR-543. Transfection with miR543 mimic significantly reduced TRPM7 mRNA (Figure 3B) and protein (Figure 3C) expression levels. TRPM7 mRNA expression level was higher in the cervical cancer tissues than in the paired noncancerous tissues (Figure 3D). Pearson's correlation coefficient identified a negative correlation between miR-543 and TRPM7 mRNA expression levels in 
Table I Association Between ST7-ASI Expression Level and Clinicopathological Factors in Patients with Cervical Cancer

\begin{tabular}{|c|c|c|c|}
\hline \multirow[t]{2}{*}{$\begin{array}{l}\text { Clinicopathological } \\
\text { Factor }\end{array}$} & \multicolumn{2}{|c|}{$\begin{array}{l}\text { ST7-ASI Expression } \\
\text { Level }\end{array}$} & \multirow[t]{2}{*}{ P-value } \\
\hline & $\begin{array}{l}\text { High } \\
(n=33)\end{array}$ & $\begin{array}{l}\text { Low } \\
(n=32)\end{array}$ & \\
\hline $\begin{array}{l}\text { Age } \\
\qquad 55 \text { years } \\
\geq 55 \text { years }\end{array}$ & $\begin{array}{l}13 \\
20\end{array}$ & $\begin{array}{l}15 \\
17\end{array}$ & 0.613 \\
\hline $\begin{array}{l}\text { Tumor size } \\
\qquad 4 \mathrm{~cm} \\
\geq 4 \mathrm{~cm}\end{array}$ & $\begin{array}{l}16 \\
17\end{array}$ & $\begin{array}{l}11 \\
21\end{array}$ & 0.609 \\
\hline $\begin{array}{l}\text { HPV infection } \\
\qquad \begin{array}{l}(-) \\
(+)\end{array}\end{array}$ & $\begin{array}{l}14 \\
19\end{array}$ & $\begin{array}{l}17 \\
15\end{array}$ & 0.269 \\
\hline $\begin{array}{l}\text { Histological } \\
\text { classification } \\
\text { Squamous } \\
\text { Adenocarcinoma } \\
\text { Adenosquamous } \\
\text { carcinoma }\end{array}$ & $\begin{array}{l}22 \\
10 \\
1\end{array}$ & $\begin{array}{l}24 \\
8 \\
0\end{array}$ & 0.524 \\
\hline $\begin{array}{l}\text { Histological grade } \\
\text { High differentiation } \\
\text { Medium differentiation } \\
\text { Low differentiation }\end{array}$ & $\begin{array}{l}15 \\
13 \\
5\end{array}$ & $\begin{array}{l}14 \\
12 \\
6\end{array}$ & 0.928 \\
\hline $\begin{array}{l}\text { FIGO stage } \\
\text { I-II } \\
\text { III-IV }\end{array}$ & $\begin{array}{l}10 \\
23\end{array}$ & $\begin{array}{l}18 \\
14\end{array}$ & 0.046 \\
\hline $\begin{array}{l}\text { Lymph node } \\
\text { metastasis } \\
\text { Absence } \\
\text { Present }\end{array}$ & $\begin{array}{l}12 \\
21\end{array}$ & $\begin{array}{l}22 \\
10\end{array}$ & 0.014 \\
\hline $\begin{array}{l}\text { Depth of cervical } \\
\text { invasion } \\
<2 / 3 \\
\geq 2 / 3\end{array}$ & $\begin{array}{l}15 \\
18\end{array}$ & $\begin{array}{l}24 \\
8\end{array}$ & 0.023 \\
\hline
\end{tabular}

the 65 cervical cancer tissues (Figure 3E; $\mathrm{r}=-0.5148, \mathrm{P}<$ 0.0001). To examine direct binding to the predicted site, luciferase reporter assay was conducted in $\mathrm{C}-33 \mathrm{~A}$ and $\mathrm{SiHa}$ cells after cotransfection with miR-543 mimic or miR-NC and TRPM7-wt or TRPM7-mut. It was revealed that ectopic miR-543 expression decreased the luciferase activity of TRPM7-wt but not of TRPM7-mut in C-33A and SiHa cells (Figure 3F), indicating direct binding of miR-543 and TRPM7 3'-UTR.
Based on these results, we next examined whether ST7AS1 participated in the modulation of TRPM7 expression in cervical cancer cells. TRPM7 mRNA (Figure 3G) and protein (Figure $3 \mathrm{H}$ ) expression levels notably decreased in C-33A and SiHa cells after transfection with si-ST7-AS1. Importantly, TRPM7 mRNA expression was positively correlated with ST7-AS1 expression in the 65 cervical cancer tissues (Figure 3I; $\mathrm{r}=0.5276, \mathrm{P}<0.0001$ ). Rescue experiments were performed to determine whether ST7-AS1 functions as a molecular sponge of miR-543 to manage TRPM7 expression in cervical cancer cells. Initially, qRT-PCR analysis confirmed the efficiency of the miR-543 inhibitor (Figure 3J). si-ST7-AS1 along with miR-543 inhibitor or $\mathrm{NC}$ inhibitor was introduced into $\mathrm{C}-33 \mathrm{~A}$ and $\mathrm{SiHa}$ cells, followed by detection of miR-543, TRPM7 mRNA, and TRPM7 protein expression levels. Increase in miR-543 expression level induced by ST7-AS1 depletion was reversed following miR-543 inhibitor cotransfection (Figure 3K). Decrease in TRPM7 mRNA (Figure 3L) and protein (Figure 3M) expression levels mediated by si-ST7-AS1 transfection was reversed by miR-543 inhibition. Consequently, TRPM7 is a direct downstream target of miR-543 in cervical cancer cells, and its expression is positively regulated by ST7-AS1 through miR-543 sponging.

\section{TRPM7 Exerts Oncogenic Actions in Cervical Cancer Cells}

TRPM7 upregulation in cervical cancer motivated the hypothesis that TRPM7 is pro-oncogenic. To test this hypothesis, si-TRPM7 or si-NC was transfected into C-33A and SiHa cells. Western blotting confirmed that TRPM7 protein expression was effectively silenced by siTRPM7 (Figure 4A). Cell proliferation was dramatically suppressed in C-33A and SiHa cells after si-TRPM7 transfection (Figure 4B). Furthermore, TRPM7 inhibition evidently increased $\mathrm{C}-33 \mathrm{~A}$ and $\mathrm{SiHa}$ cell apoptosis (Figure 4C). Finally, decreased TRPM7 expression reduced C-33A and $\mathrm{SiHa}$ cell migration (Figure 4D) and invasion (Figure 4E). Thus, TRPM7 acts as an oncogene in cervical cancer cells.

\section{Increased miR-543/TRPM7 Axis Output Abrogates ST7-ASI Deficiency-Mediated Effects in Cervical Cancer Cells}

Rescue experiments were further performed to assess the mechanisms of ST7-AS1 in inducing the aggressive phenotype of cervical cancer cells. On one hand, ST7-AS1-depleted 
A
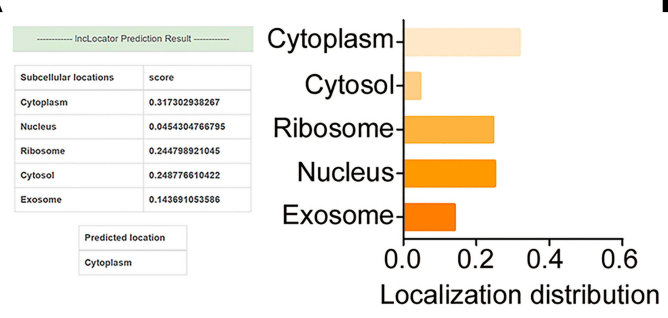

B

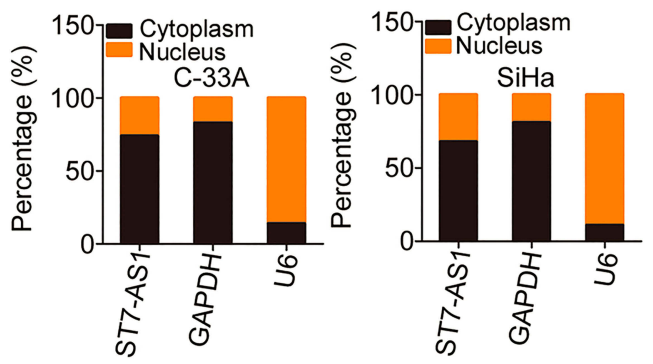

E

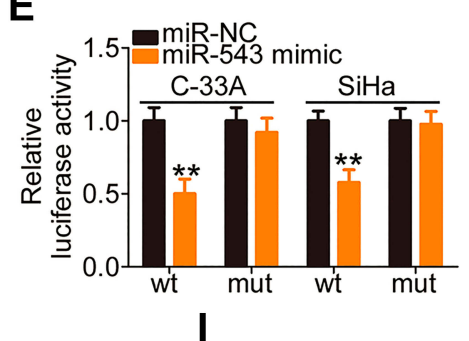

D

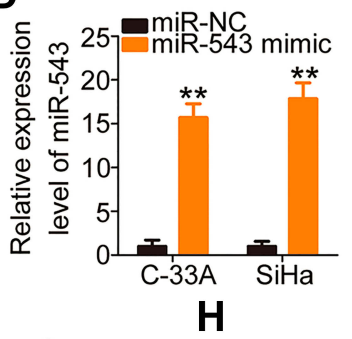

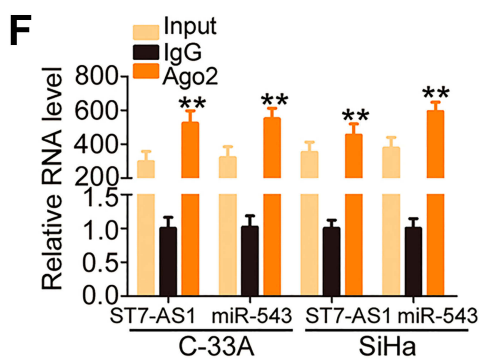

G

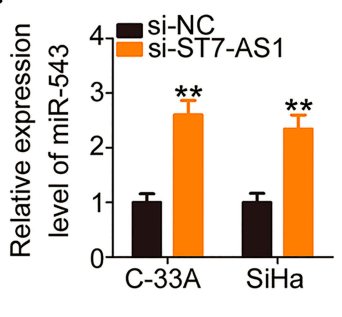

I

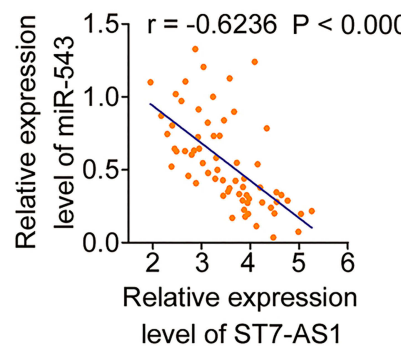

Figure 2 ST7-ASI acts as a molecular sponge of miR-543 in cervical cancer. (A) IncLocator was used to predict the subcellular localization of ST7-ASI. (B) Subcellular fractionation followed by qRT-PCR showed that ST7-ASI is mostly localized in the cytoplasm of C-33A and SiHa cells. (C) starBase 3.0 was used to predict the binding sequences between ST7-ASI and miR-543. The mutant binding site is also shown. (D) C-33A and SiHa cells were transfected with miR-543 mimic or miR-NC. Transfected cells were subjected to qRT-PCR for transfection efficiency analysis. (E) Luciferase reporter assay revealed the effect of miR-543 upregulation on luciferase activity in C-33A and SiHa cells transfected with ST7-ASI-wt or ST7-ASI-mut reporter plasmid. (F) RIP assay was performed to analyze the interactions between ST7-ASI and miR-543 in C-33A and SiHa cells. ST7-ASI and miR-543 could be immunoprecipitated with anti-Ago2. (G) The regulatory effects of ST7-ASI knockdown on miR-543 expression in C-33A and SiHa cells were determined by qRT-PCR. (H) qRT-PCR detected miR-543 expression in 65 cervical cancer and paired noncancerous tissues. (I) Expression correlation of ST7-ASI and miR-543 in the cervical cancer tissues was analyzed by Pearson's correlation coefficient $(r=-0.6236, P<0.000 I)$. $* P<0.05$ and $* * P<0.01$.

C-33A and SiHa cells were further transfected with miR-543 inhibitor or NC inhibitor, following which cotransfected cells were subjected to a series of functional experiments. CCK-8 assay and flow cytometry illuminated that miR-543 inhibitor transfection abrogated the impacts of ST7-AS1 deficiency on the proliferation (Figure 5A) and apoptosis (Figure 5B) of $\mathrm{C}-33 \mathrm{~A}$ and $\mathrm{SiHa}$ cells. Transwell migration and invasion assays revealed that the migratory (Figure $5 \mathrm{C}$ ) and invasive (Figure 5D) abilities of C-33A and SiHa cells were impaired after ST7-AS1 knockdown, which were restored by miR-543 downregulation.

On the other hand, si-ST7-AS1 in combination with pcDNA3.1/TRPM7 or pcDNA3.1 plasmid was transfected into C-33A and SiHa cells. The efficiency of pcDNA3.1/ TRPM7 was determined by Western blotting (Figure 5E). Restoration of TRPM7 expression notably attenuated ST7AS1 downregulation-mediated inhibition of C-33 A and $\mathrm{SiHa}$ cell proliferation (Figure 5F). In addition, reduced ST7-AS1 expression promoted $\mathrm{C}-33 \mathrm{~A}$ and $\mathrm{SiHa}$ cell apoptosis and the reintroduction of TRPM7 significantly abolished this effect (Figure 5G). Transwell migration and invasion assays delineated a marked impairment of the migratory (Figure $5 \mathrm{H}$ ) and invasive (Figure 5I) abilities of si-ST7-AS1-transfected $\mathrm{C}-33 \mathrm{~A}$ and $\mathrm{SiHa}$ cells, and this impairment was reversed by TRPM7 upregulation. These results suggest that increased miR-543/TRPM7 axis output counteracted the ST7-AS1 deficiency-mediated cancer-inhibitory actions, implying the role of the novel ST7-AS1/miR-543/TRPM7 axis in the genesis of cervical cancer.

\section{ST7-ASI Silencing Alleviates Cervical Cancer Cells Growth in vivo}

Xenograft experiment was performed to test whether ST7-AS1 depletion suppresses the growth of cervical 
A

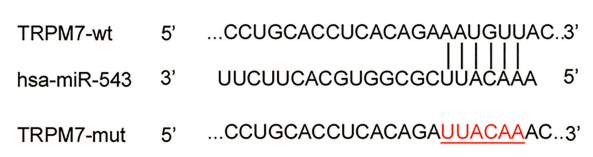

D

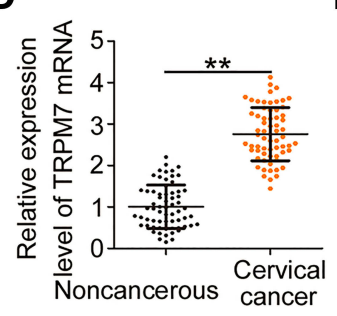

E

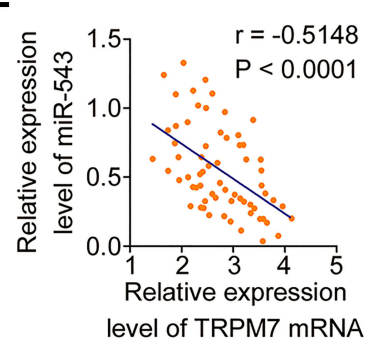

B

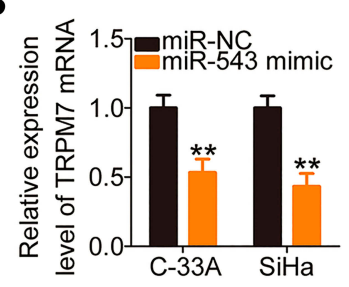

F

C

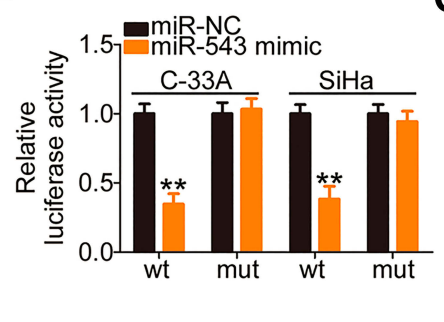

G
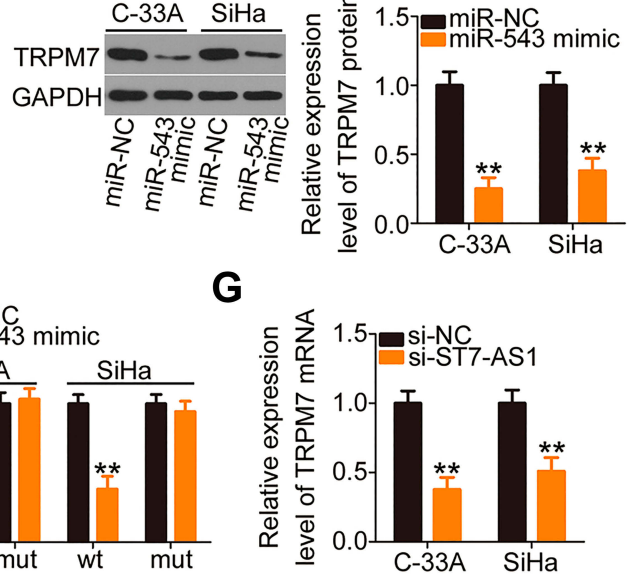

H

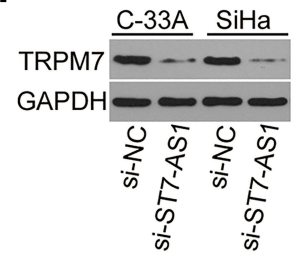

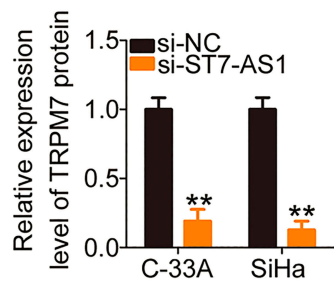

I

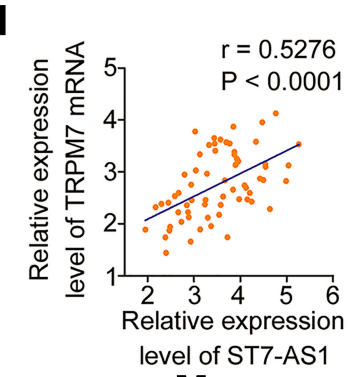

M

J

K

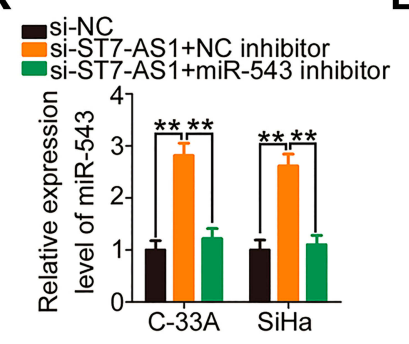

L

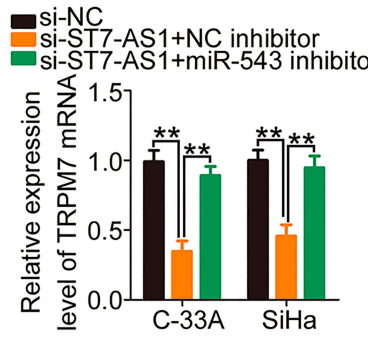

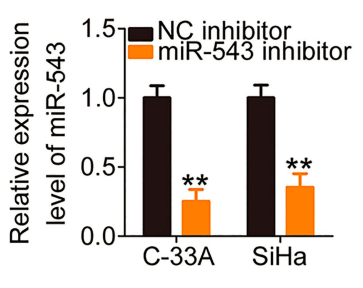



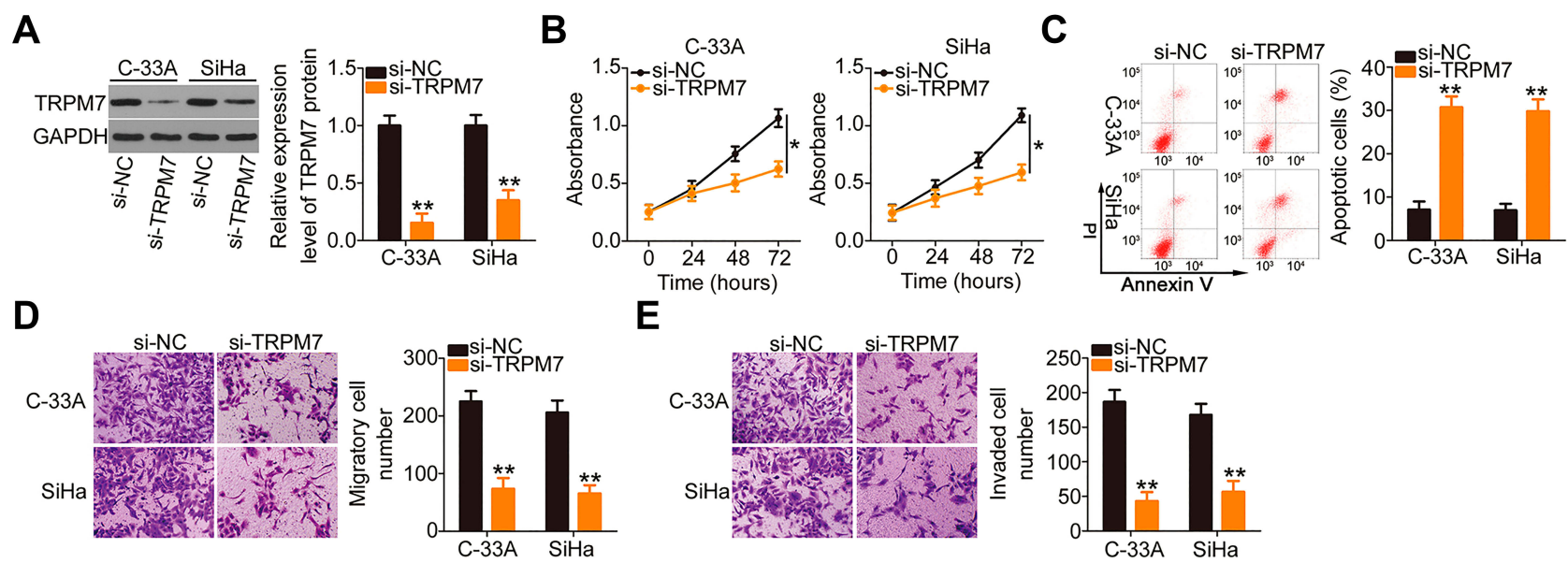

$\mathbf{E}$

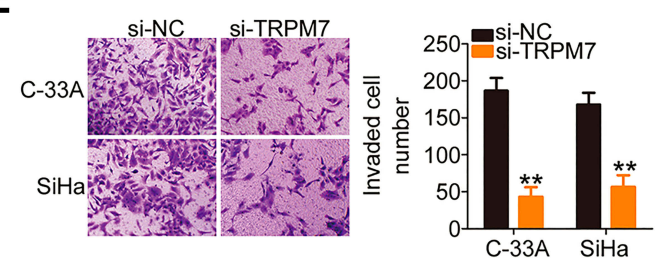

Figure 4 TRPM7 knockdown inhibits C-33A and SiHa cell proliferation, migration, and invasion but promotes apoptosis in vitro. (A) Western blotting was performed to measure TRPM7 protein expression in C-33A and SiHa cells transfected with si-TRPM7 or si-NC. (B-E) TRPM7-deficient C-33A and SiHa cells were subjected to CCK-8 assay, flow cytometry, transwell migration assay, and transwell invasion assay for the detection of cell proliferation, apoptosis, migration, and invasion, respectively. $* \mathrm{P}<0.05$ and $* * P<0.01$.

observations indicated that reduced ST7-AS1 expression suppressed the growth of cervical cancer cells in vivo by upregulating miR-543 and decreasing TRPM7 expression.

\section{Discussion}

In recent years, the expression profiles of lncRNAs and their roles in cervical oncogenesis and progression have received widespread attention. ${ }^{30}$ Therefore, understanding the mechanistic details of cervical cancer-related lncRNAs in regulating cell behaviors is essential to identify useful diagnostic and therapeutic targets for cervical cancer. Various lncRNAs are closely linked to cervical cancer. ${ }^{31-}$ ${ }^{33}$ However, detailed studies are scarce. In the present study, ST7-AS1 expression in cervical cancer tissues and cell lines was detected and its biological roles were investigated in the aggressive phenotype of this malignancy both in vitro and in vivo. Importantly, mechanisms underlying the effects of ST7-AS1 on cervical cancer progression were further clarified.

ST7-AS1 is upregulated in gastric cancer tissues and cell lines, and high ST7-AS1 expression is significantly correlated with tumor stage and size. ${ }^{21}$ Moreover, ST7AS1 is highly expressed in laryngeal squamous cell carcinoma and is closely related to tumor-node-metastasis stage, metastasis, and smoking and drinking status. ${ }^{22}$ Patients with laryngeal squamous cell carcinoma with high ST7-AS1 expression exhibited shorter overall survival than those with low ST7-AS1 expression. ${ }^{22}$ Nonetheless, the expression patterns of ST7-AS1 in cervical cancer have not been completely characterized. In the present study, increased ST7-AS1 expression was observed in both cervical cancer tissues and cell lines. ST7-AS1 overexpression was significantly correlated with a high FIGO stage, frequent lymph node metastasis, deep cervical invasion, and short overall survival in patients with cervical cancer.

Biologically, ST7-AS1 knockdown suppresses gastric cancer cell viability and motility and promotes apoptosis and cell cycle arrest. ${ }^{21}$ In laryngeal squamous cell carcinoma, ST7-AS1 downregulation inhibits migration and tumorsphere formation in vitro and reduces tumor growth in vivo. ${ }^{22}$ However, the regulatory functions of ST7-AS1 in cervical cancer have not been explored previously. In this study, ST7AS1 depletion hindered cervical cancer cell proliferation, migration, and invasion but promoted apoptosis in vitro. In addition, ST7-AS1 deficiency restricted the growth of cervical cancer cells in vivo.

The molecular events mediating the pro-oncogenic actions of ST7-AS1 were thoroughly elucidated. Considerable evidence suggests that cytoplasmic lncRNAs act as competing endogenous RNAs (ceRNAs) by binding to certain miRNAs. Consequently, IncRNAs reverse the miRNA-induced suppression of target genes. ${ }^{34-36}$ lncLocator analysis and subcellular fractionation revealed that ST7-AS1 is mostly localized in the cytoplasm, providing a theoretical basis for its role as a ceRNA. Bioinformatics analysis showed that miR-543 harbors binding sites complementary to ST7-AS1, and this result was subsequently confirmed by luciferase reporter and RIP 
A

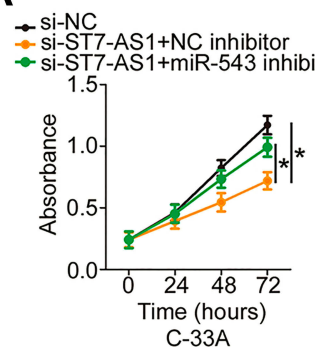

C

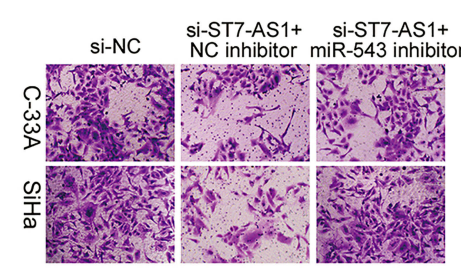

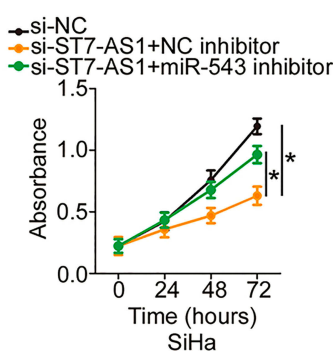

$\mathrm{SiHa}$

B

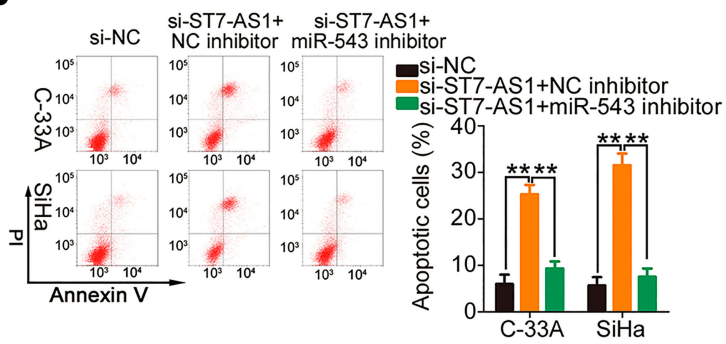

D

E

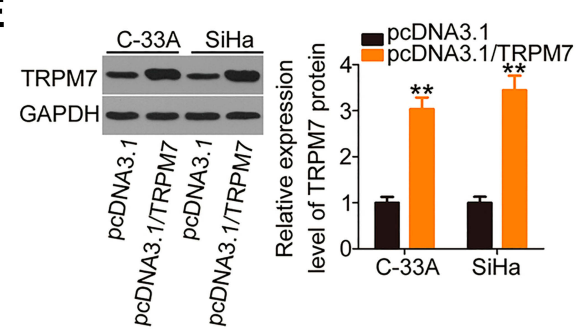

Si-NC
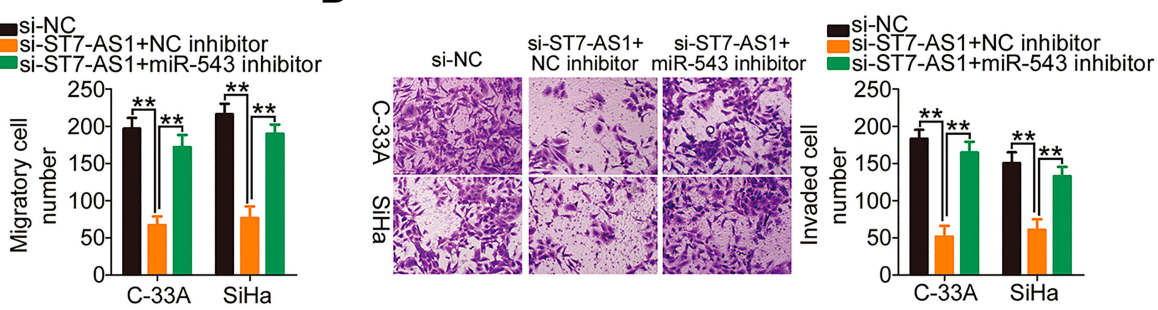

$F$

si-NC
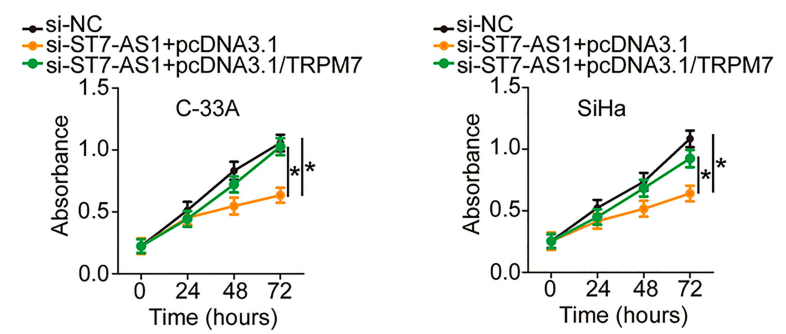

G

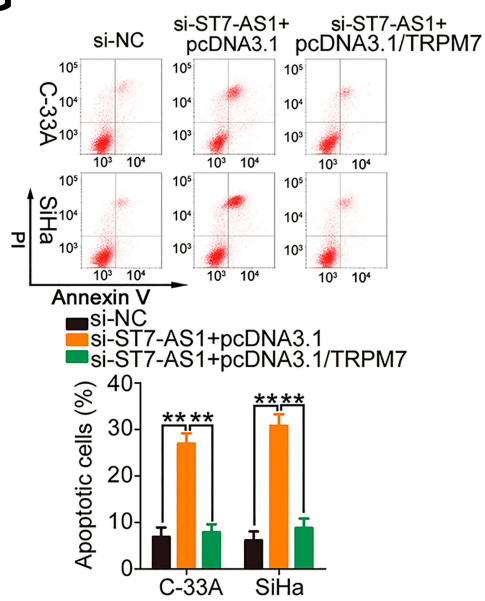

H
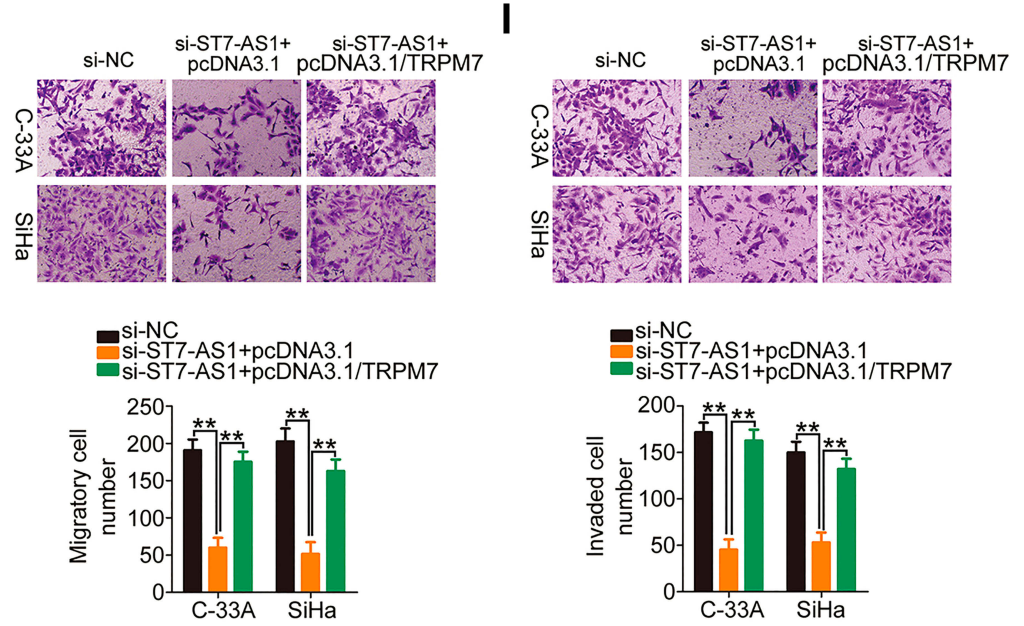

Figure 5 miR-543 downregulation or TRPM7 upregulation abrogates the effects of ST7-ASI silencing on C-33A and SiHa cells. (A-D) si-ST7-ASI along with miR-543 or NC inhibitor was cotransfected into C-33A and SiHa cells. CCK-8 assay, flow cytometry, transwell migration assay, and transwell invasion assay were performed to analyze cell proliferation, apoptosis, migration, and invasion, respectively. (E) TRPM7 protein expression in C-33A and SiHa cells was examined following pcDNA3.I or pcDNA3.I/ TRPM7 transfection. (F-I) si-ST7-ASI along with pcDNA3.I or pcDNA3.I/TRPM7 was cotransfected into C-33A and SiHa cells. Cell proliferation, apoptosis, migration, and invasion were analyzed using CCK-8 assay, flow cytometry, transwell migration assay, and transwell invasion assay, respectively. $* \mathrm{P}<0.05$ and $* * \mathrm{P}<0.0 \mathrm{I}$.

assays. Furthermore, miR-543 was overexpressed in the 65 cervical cancer tissues compared with that in the paired noncancerous tissues. miR-543 expression was inversely correlated with ST7-AS1 expression in cervical cancer tissues. Notably, miR-543 expression increased in the cervical cancer cells when ST7-AS1 was knocked down.
Decreased miR-543 expression in cervical cancer has been reported, ${ }^{29,37}$ which is consistent with the present observations. High miR-543 expression is notably associated with adverse clinicopathological characteristics in patients with cervical cancer. ${ }^{29}$ Functionally, miR-543 acts as an anti-oncogenic miRNA in cervical 
A

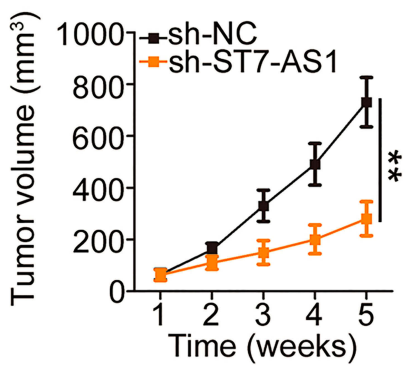

D

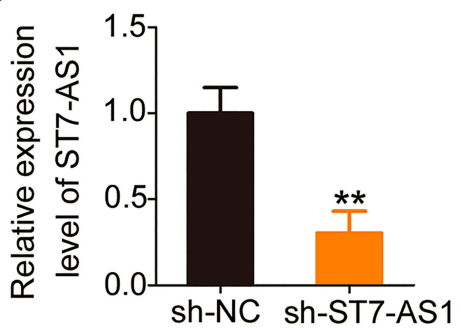

B

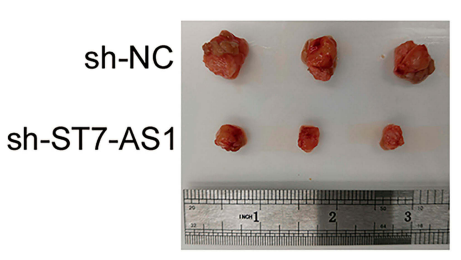

E

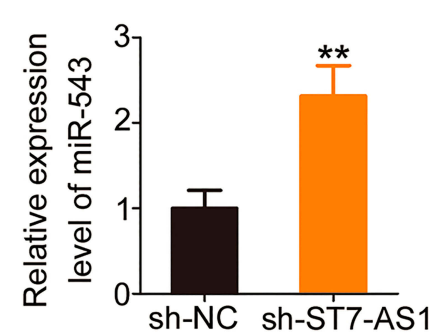

C

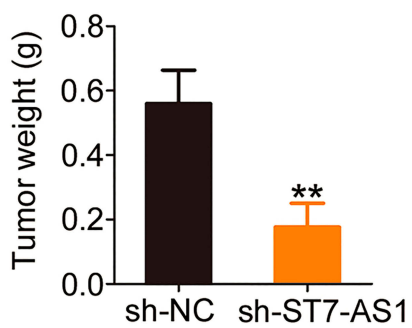

F

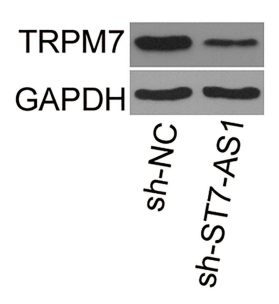

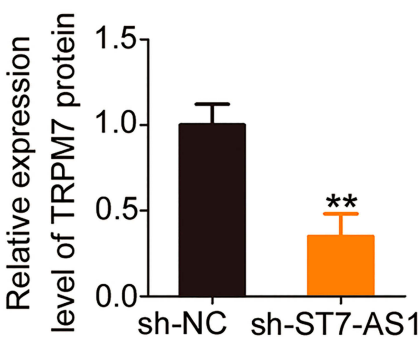

Figure 6 ST7-ASI knockdown suppresses the growth of cervical cancer cells in vivo. (A) Volume of subcutaneous xenografts was measured weekly, and the growth curve was plotted accordingly. (B) Representative photograph of tumor xenografts obtained from the sh-ST7-ASI and sh-NC groups. (C) Weight of tumor xenografts was recorded in the 5th week. (D and E) qRT-PCR was performed to measure ST7-ASI and miR-543 expressions in tumor xenografts derived from HeLa cells stably expressing sh-ST7-ASI or sh-NC. (F) TRPM7 protein expression in tumor xenografts was examined by Western blotting. **P $<0.01$.

cancer and is implicated in the regulation of cell proliferation, colony formation, cell apoptosis, cell cycle, and cancer metastasis in vitro and tumor growth in vivo. ${ }^{29}$ In lieu of earlier research, ${ }^{29}$ a series of mechanism studies verified TRPM7 as a direct downstream target of miR-543 in cervical cancer cells. Further investigation revealed that ST7-AS1 depletion suppressed TRPM7 expression, and this effect was rescued by miR-543 inhibition. Notably, a positive correlation was observed between ST7-AS1 and TRPM7 in cervical cancer tissues. Importantly, miR-543 inhibition or TRPM7 overexpression counteracted the suppressive effects of ST7-AS1 depletion on the malignant phenotype of cancer cells. Overall, ST7-AS1 acts as a ceRNA to restore TRPM7 expression via miR-543 sponging. Thus, the novel ST7-AS1/miR-543/TRPM7 axis drives the genesis of cervical cancer both in vitro and in vivo.

\section{Conclusion}

ST7-AS1 promotes cervical cancer progression through TRPM7 upregulation via miR-543 sponging. The present study highlights the importance of the novel ST7-AS1 /miR-543/TRPM7 axis in cervical cancer progression, suggesting that this pathway can serve as a promising therapeutic target for cervical cancer.

\section{Disclosure}

The authors report no conflicts of interest in this work.

\section{References}

1. Ventriglia J, Paciolla I, Pisano C, et al. Immunotherapy in ovarian, endometrial and cervical cancer: state of the art and future perspectives. Cancer Treat Rev. 2017;59:109-116. doi:10.1016/j. ctrv.2017.07.008

2. Santamaria-Ulloa C, Valverde-Manzanares C. Inequality in the incidence of cervical cancer: costa rica 1980-2010. Front Oncol. 2018;8:664. doi:10.3389/fonc.2018.00664

3. Arbyn M, Castellsague X, de Sanjose S, et al. Worldwide burden of cervical cancer in 2008. Ann Oncol. 2011;22(12):2675-2686. doi:10.1093/annonc/mdr015

4. Ghebre RG, Grover S, Xu MJ, Chuang LT, Simonds H. Cervical cancer control in HIV-infected women: past, present and future. Gynecologic Oncol Rep. 2017;21:101-108. doi:10.1016/j. gore.2017.07.009

5. Berkowitz RP. 2012 updated consensus guidelines for the management of abnormal cervical cancer screening tests and cancer precursors. Obstet Gynecol. 2013;122(2 Pt 1):393. doi:10.1097/ AOG.0b013e31829b61d6

6. Gibb EA, Brown CJ, Lam WL. The functional role of long non-coding RNA in human carcinomas. Mol Cancer. 2011;10:38. doi:10.1186/ 1476-4598-10-38

7. Kung JT, Colognori D, Lee JT. Long noncoding RNAs: past, present, and future. Genetics. 2013;193(3):651-669. doi:10.1534/ genetics.112.146704

8. Fatica A, Bozzoni I. Long non-coding RNAs: new players in cell differentiation and development. Nat Rev Genet. 2014;15(1):7-21. doi: $10.1038 / \mathrm{nrg} 3606$

9. Fang Y, Fullwood MJ. Roles, functions, and mechanisms of long non-coding RNAs in cancer. Genomics Proteomics Bioinformatics. 2016;14(1):42-54. doi:10.1016/j.gpb.2015.09.006 
10. Zhang X, Wang W, Zhu W, et al. Mechanisms and functions of long non-coding RNAs at multiple regulatory levels. Int $J \mathrm{Mol} S \mathrm{Sci}$. 2019;20:22. doi:10.3390/ijms20225573

11. Arredondo-Robles AV, Rodriguez-Lopez KP, Avila-Aviles RD. Long non-coding RNAs in cervical cancer. J Appl Genet. 2020. doi:10.1007/s13353-020-00545-9

12. Li X, Han X, Wei P, Yang J, Sun J. Knockdown of lncRNA CCAT1 enhances sensitivity of paclitaxel in prostate cancer via regulating miR-24-3p and FSCN1. Cancer Biol Ther. 2020;1-11. doi:10.1080/ 15384047.2020.1769418

13. Dou X, Zhou Q, Wen M, et al. Long noncoding RNA FOXD2-AS1 promotes the malignancy of cervical cancer by sponging MicroRNA-760 and upregulating hepatoma-derived growth factor. Front Pharmacol. 2019;10:1700. doi:10.3389/fphar.2019.01700

14. Xie F, Xie G, Sun Q. Long noncoding RNA DLX6-AS1 promotes the progression in cervical cancer by targeting miR-16-5p/ARPP19 axis. Cancer Biother Radiopharm. 2020. doi:10.1089/cbr.2019.2960

15. Braconi C, Henry JC, Kogure T, Schmittgen T, Patel T. The role of microRNAs in human liver cancers. Semin Oncol. 2011;38 (6):752-763. doi:10.1053/j.seminoncol.2011.08.001

16. Bartel DP. MicroRNAs: genomics, biogenesis, mechanism, and function. Cell. 2004;116(2):281-297. doi:10.1016/S0092-8674(04) 00045-5

17. Engels BM, Hutvagner G. Principles and effects of microRNA-mediated post-transcriptional gene regulation. Oncogene. 2006;25(46):6163-6169. doi:10.1038/sj.onc.1209909

18. Zou X, Zhu C, Zhang L, et al. MicroRNA-708 suppresses cell proliferation and enhances chemosensitivity of cervical cancer cells to cDDP by negatively targeting timeless. Onco Targets Ther 2020;13:225-235. doi:10.2147/OTT.S227015

19. Feng J, Wang T. MicroRNA-873 serves a critical role in human cervical cancer proliferation and metastasis via regulating glioma-associated oncogene homolog 1. Exp Ther Med. 2020;19 (2):1243-1250. doi:10.3892/etm.2019.8348

20. Jin Y, Zhou X, Yao X, Zhang Z, Cui M, Lin Y. MicroRNA-612 inhibits cervical cancer progression by targeting NOB1. J Cell Mol Med. 2020;24. doi:10.1111/jcmm.14985

21. Cai S, Weng Y, Liu P, Miao F. Knockdown of ST7-AS1 inhibits migration, invasion, cell cycle progression and induces apoptosis of gastric cancer. Oncol Lett. 2020;19(1):777-782. doi:10.3892/ ol.2019.11145

22. Qin $\mathrm{H}, \mathrm{Xu}$ J, Gong L, Jiang B, Zhao W. The long noncoding RNA ST7-AS1 promotes laryngeal squamous cell carcinoma by stabilizing CARM1. Biochem Biophys Res Commun. 2019;512(1):34-40. doi:10.1016/j.bbrc.2019.02.057

23. Guo Q, Zhang Q, Lu L, Xu Y. Long noncoding RNA RUSC1-AS1 promotes tumorigenesis in cervical cancer by acting as a competing endogenous RNA of microRNA-744 and consequently increasing Bcl-2 expression. Cell Cycle. 2020;19(10):1222-1235. doi:10.1080/ 15384101.2020.1749468
24. Sun Y, Cheng Y, Zhang Y, Han K. MicroRNA-889-3p targets FGFR2 to inhibit cervical cancer cell viability and invasion. Exp Ther Med. 2019;18(2):1440-1448. doi:10.3892/etm.2019.7675

25. Wang WF, Sun R, Zhao XY.[Clinical analysis of ovarian and cervical malignant lymphoma]. Zhonghua Fu Chan Ke Za Zhi. 1994;29 (1):23-26. Chinese.

26. Diaz-Feijoo B, Luna-Guibourg R, Cabrera S, Manrique S, GilMoreno A. Laparoscopic extraperitoneal pelvic lymph node debulking in locally advanced cervical cancer. J Minim Invasive Gynecol. 2019;26(2):366. doi:10.1016/j.jmig.2018.05.008

27. Mastroianni M, Di Vagno G, Melilli GA, et al. [Combination of cisplatin and vinorelbin in the neoadjuvant treatment of locally advanced cervical carcinoma. Phase II study]. Minerva Ginecol. 2000;52(4):95-98. Italian.

28. Kim M, Suh DH, Lee KH, et al. Major clinical research advances in gynecologic cancer in 2019. J Gynecol Oncol. 2020;31(3):e48. doi:10.3802/jgo.2020.31.e48

29. Liu X, Gan L, Zhang J. miR-543 inhibites cervical cancer growth and metastasis by targeting TRPM7. Chem Biol Interact. 2019;302:83-92. doi:10.1016/j.cbi.2019.01.036

30. Aalijahan H, Ghorbian S. Long non-coding RNAs and cervical cancer. Exp Mol Pathol. 2019;106:7-16. doi:10.1016/j. yexmp.2018.11.010

31. Zhang Y, Wu D, Wang D. Long non-coding RNA ARAP1-AS1 promotes tumorigenesis and metastasis through facilitating proto-oncogene c-Myc translation via dissociating PSF/PTB dimer in cervical cancer. Cancer Med. 2020;9(5):1855-1866.

32. Lai SY, Guan HM, Liu J, et al. Long noncoding RNA SNHG12 modulated by human papillomavirus $16 \mathrm{E} 6 / \mathrm{E} 7$ promotes cervical cancer progression via ERK/Slug pathway. J Cell Physiol. 2020.

33. Li R, Liu J, Qi J. Knockdown of long non-coding RNA CCAT1 suppresses proliferation and EMT of human cervical cancer cell lines by down-regulating Runx2. Exp Mol Pathol. 2020;113:104380. doi:10.1016/j.yexmp.2020.104380

34. Wei Y, Wang Z, Zong Y, Deng D, Chen P, Lu J. LncRNA MFI2-AS1 promotes HCC progression and metastasis by acting as a competing endogenous RNA of miR-134 to upregulate FOXM1 expression. Biomed Pharmacother. 2020;125:109890. doi:10.1016/j. biopha.2020.109890

35. Sun Y, Han C. Long non-coding RNA TMPO-AS1 promotes cell migration and invasion by sponging miR-140-5p and inducing SOX4-mediated EMT in gastric cancer. Cancer Manag Res. 2020;12:1261-1268. doi:10.2147/CMAR.S235898

36. Wang L, Wang C, Wu T, Sun F. Long non-coding RNA TP73-AS1 promotes TFAP2B-mediated proliferation, metastasis and invasion in retinoblastoma via decoying of miRNA-874-3p. J Cell Commun Signal. 2020;14. doi:10.1007/s12079-020-00550-X

37. Ma Z, Gu G, Pan W, Chen X. LncRNA PCAT6 accelerates the progression and chemoresistance of cervical cancer through up-regulating ZEB1 by sponging miR-543. Onco Targets Ther. 2020;13:1159-1170. doi:10.2147/OTT.S232354

OncoTargets and Therapy

Dovepress

\section{Publish your work in this journal}

OncoTargets and Therapy is an international, peer-reviewed, open access journal focusing on the pathological basis of all cancers, potential targets for therapy and treatment protocols employed to improve the management of cancer patients. The journal also focuses on the impact of management programs and new therapeutic

agents and protocols on patient perspectives such as quality of life, adherence and satisfaction. The manuscript management system is completely online and includes a very quick and fair peer-review system, which is all easy to use. Visit http://www.dovepress.com/ testimonials.php to read real quotes from published authors.

Submit your manuscript here: https://www.dovepress.com/oncotargets-and-therapy-journal 